\title{
Diagnostic survey in a regional psychotherapy unit
}

\author{
Joanne Evans, Jenny Hartman and Stephen Gladwell
}

\begin{abstract}
Asecasment of pationts referred for poychotherapy has more commonly conalded of a poychoctynamic caseasment with less emphosts on a formal poychiotile cloconots, whoreas the reveres tends io be the case in the general poychiotile senvices. Within the National Hecill Service there are close links between the two services. A common trams of reference regarding the delinition of the potient groups ueing the services could improve communication, tho planning and evatuation of specilic treatmont programmos, and outcome studbes. A retroepective coise-note study was coniled out at a regional poychothercapy unit in order to define the population referred botween 1991 and 1992 cccording to KCD-10 (WHO, 1992 ).
\end{abstract}

The Royal College of Psychiatrists has recently published guidelines on improving the training of psychiatrists in psychotherapy, thereby placing more emphasis on this method of treatment (Grant et al, 1993). At the same time as financial constraints within the National Health Service (NHS) continue, the value of psychotherapy services is again under scrutiny (Fahy \& Wessely, 1993). The general trend in psychotherapy services for the use of individual psychodynamic assessments without necessarily assigning a formal diagnosis has made evaluation of services more difficult. one particular consequence being a lack of data concerning the type of patient referred for psychotherapy within the NHS. The general psychiatric services place more emphasis on formal psychiatric diagnosis, so that despite close links between the two services, survey issues are difficult to communicate and compare. The tenth revision of the International Classification of Diseases (ICD-10; World Health Organization, 1992) provides more meaningful diagnostic categories for use in a psychotherapy setting than previous editions, as well as a common frame of reference for both services.

In order to determine the range of psychiatric disorder and psychological distress of patients referred to the Uffculme Clinic, the West Midland's regional centre for psychodynamic psychotherapy, a diagnostic survey was carried out. The clinic offers various forms of psychotherapy, both group and individual, on an out-patient basis and in a multidisciplinary setting. There are specific service provisions for certain identified patient groups, for example couple therapy or victims of sexual abuse.

\section{The study}

A retrospective case-note study of all referrals to the clinic from 1st January 1991 to 31st December 1992 was undertaken. The referrals were divided into two groups; those who underwent a full assessment and those who did not attend. A full assessment consisted of a minimum of 1.5 hours unstructured interview by a member of the multidisciplinary team. Questionnaires concerning the patient's history, completed during the assessment period, were also used. Age, gender, source of referral and diagnosis according to ICD-10 categories were recorded. In addition, a history of childhood sexual abuse was specifically looked for and noted (codes Z61.4 and Z61.5).

Because of the numbers involved and the difficulty in assigning an exact diagnostic category, some categories were combined into diagnostic bands. These were:

- Combined anxiety disorders F40 and F41 (excluding F41.2, mixed anxiety and depresstve disorder which was categorised under F43)

- A combined group for reaction to severe stress and adjustment disorders, F43 excluding post traumatic stress disorder F43.1. Post traumatic stress disorder was considered as a separate category

- Mood disorders F30-39

- Combined affective disorders F30-39, F43

- Obsesstve compulstve disorder F42

- Non-organic non-affective psychosis F20F29 
- Gender identity disorder F64

- Sexual dysfunction F52

- Eating disorders F50

- Psychoactive substance abuse F10-F19

- Dissociattve and somatoform disorders F44 and F45

- Organic disorders FOO-FO9

The continuum of personality traits and personality disorder was considered as one group encompassing F60-F63 and including problems categorised under Z73 (problems related to life-management difficulty). The category 'personality difficulties' was created in recognition of a large group of maladaptive personalities who might not fulfil the narrow operational criteria for personality disorder, yet experience considerable adverse social effects (Rutter, 1987; Stone, 1993). Due to the fact that couple therapy is provided at the clinic, a separate group for those with specific problems in relationship with spouse or partner but no other difficulty, 263.0, was included. There were also categories for no mental illness, and unkmown diagnosis, due to insufficient information in the case-notes. Because of the limitations of a retrospective case-note study, it was felt that the use of a multiaxial diagnostic system would not be valid. The diagnosis precipitating referral rather than personality disorder or trait was used if both coexisted. This would inevitably underestimate the degree of psychopathology in the group as a whole, but was considered preferable to drawing conclusions from less reliable data. Inter-rater reliability was determined using the kappa statistic.

\section{Findings}

A total of 1352 referrals were made of whom 993 were assessed. Six case notes could not be traced. The non-attendance rate was therefore $27 \%$. Gender distribution was $42 \%$ males and $58 \%$ females, in both assessed and non-attendance groups. The age distribution of the assessed patients was: 6\% under 20 years, 37\% aged 21-30years, 30\% aged $31-40$ years, $18 \%$ aged $41-50$ years, $5 \%$ aged $51-$ 60 years, $1 \%$ aged $61-70$ years, over 70 years was less than $1 \%$ and $2 \%$ were unknown. Within the assessed group, $8 \%$ had a recorded history of CSA in 1991 and $12.5 \%$ in 1992. However, within the CSA group, the percentage of males increased from $6 \%$ to $17 \%$ over the two years.
The source of the referrals were: general practitioner 69\%; psychiatrist 21\%; psychologist 5\%; social worker $1 \%$, and other sources $4 \%$.

The percentage of assessments allocated to each category are shown in Table 1. Kappa was calculated as $\mathbf{0 . 6 1}$ for reliability for a history of CSA and 0.74 for allocation to a diagnostic group.

\section{Comment}

Despite the limitations of a retrospective casenote study (Scott, 1981), these figures show that the patients assessed had significant levels of psychological distress. The most common diagnoses were the anxiety and adjustment type disorders and personality difficulties. However, significant numbers of those with mood disorder, sexual dysfunction. eating disorders and substance abuse were recorded and, as has previously been mentioned, an underestimate of the degree of psychopathology is likely in this survey. These results may indicate a trend developing from increased pressure on the general services which results in those with a greater degree of psychological disturbance being referred for psychotherapy. Whether this is the case will be shown by future surveys; for the present it can be shown that contrary to some bellefs, it is not the worried-well who attend psychotherapy services.

The source of referral in the great majority of cases was the general practitioner, with general psychiatrists only referring one fifth of the total. There may be several factors influencing this pattern: general practitioners may bypass the general services which increasingly are percetved to be psychosis-orientated and under financial pressure. The low level of referrals with a non-affective psychotic illness (only 1.5\%) might support this, as well as there being an understanding that dynamic psychotherapy is not particularly helpful in such disorders, a belief which is also generally held at the clinic. Further research is needed to clarify the reasons for such skewed referral patterns. Despite low levels of psychotic illness, as a whole the group represents patients with severe difficulties, many of whom will be at risk of deliberate self-harm. Such patients therefore contribute to the high risk group targeted by The Health of the Nation White Paper. 
Table 1. Percentage of assessed referrals in each ICD-10 category

\begin{tabular}{|c|c|c|}
\hline Diognostic band & Percentage & KCD-10 cotogory \\
\hline 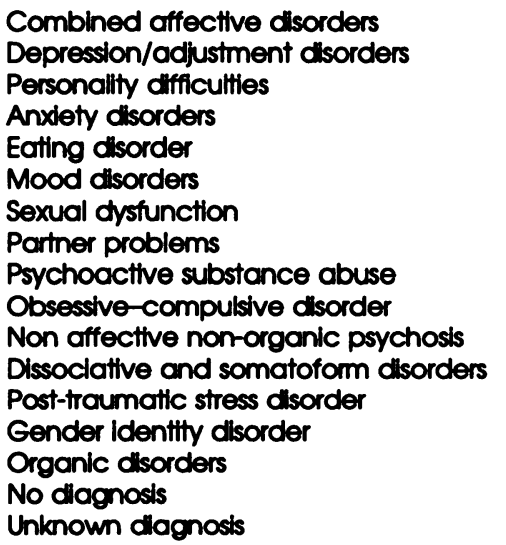 & $\begin{array}{r}34.0 \\
29.3 \\
21.0 \\
19.7 \\
6.0 \\
4.7 \\
3.0 \\
3.0 \\
2.7 \\
2.0 \\
1.5 \\
1.2 \\
1.1 \\
0.8 \\
0.3 \\
2.7 \\
1.0\end{array}$ & $\begin{array}{l}F 30-39 \text {. F43 except } 43.1 \\
\text { F43 excluding F43.1 } \\
\text { F60-63 and Z73 } \\
\text { F40-41 excluding F41.2 } \\
\text { F50 } \\
\text { F30-39 } \\
F 62 \\
Z 63.0 \\
F 10-19 \\
F 42 \\
F 20-29 \\
F 44-45 \\
F 43.1 \\
F 64 \\
F 00-09\end{array}$ \\
\hline
\end{tabular}

Early psychoanalysis used a diagnostic approach, in keeping with a medical model (Holmes, 1991). Subsequently, individual psychodynamic formulation not necessarily including a psychiatric diagnosis was considered sufficient, reflecting concern regarding the stablity of diagnoses, reliability and labelling. Despite encouragement to consider both aspects, this debate is ongoing and is reflected in the varied approach by members of the multidisciplinary team to assessment for psychotherapy. This can lead to problems and error in diagnosis when the emphasis is on psychodynamic formulation. An example of this would be post-traumatic stress disorder, where symptoms, unless specifically identified, are easy to miss, and therefore the number of these patients underestimated.

Diagnosis in psychotherapy may be difficult and constrained by several limitations. Nevertheless, it can be argued that it is an important aspect of medical audit within psychotherapy services.

\section{References}

FaHY, T. \& Wessely, S. (1993) Should purchasers pay for psychotherapy? Brtish Medical Journal, so7. 576-577.

FoNAGY, P. \& HiGGrT, A. (1989) Evaluating the performance of Departments of Psychotherapy. Psychoanalytic Psychotherapy. 4, 121-153.

GRANT, S., HowaES, J. \& WATSON, J. (1993) Guidelines for psychotherapy training as part of general professional training. Psychiatric Bulletin, 17, 695-698.

HoLMEs, J. (1991) Introduction: analytic psychotherapy. In Textbook of Psychotherapy in Psychiatric Practice (ed. J. Holmes). Churchill Livingstone.

RUTTER, M. (1987) Temperament, personality and personality disorder. British Journal of Psychiatry, 160. $443-458$.

ScorT, D. F. (1981) Research methods espectally in psychlatry. Brttsh Joumal of Hospltal Medictre, 28, 596.

STONE, M. H. (1991) Long-term outcome in personality disorders. British Joumal of Psychtatry, 162, 299-313.

WorLd HEALTH Organization. (1992) The Tenth Reviston of the International Classification of Mental and Behavioural Disorders (ICD-10). Geneva: WHO.

J. Evans, Uffculme Clinic, Queensbridge Road, Moseley, Birmingham B13 8QD 